Case Report

\title{
OUR EXPERINCE OF A CASE OF TERRIBLE TRIAD OF ELBOW
}

\author{
Siddharth M. Shetty ${ }^{1}$, Vikram Shetty ${ }^{2}$, Arjun Ballal ${ }^{3}$ \& Anoop Hegde ${ }^{4}$ \\ ${ }^{1,2}$ Associate Professors, ${ }^{3,4} \mathrm{P}$. G. Students, Department of Orthopaedic Surgery, \\ K.S. Hegde M edical Academy, Nitte University, M angalore - 575 018, Karnataka, India. \\ Correspondence : \\ Arjun Ballal \\ P.G. Student, Department of Orthopaedic Surgery \\ K.S. Hegde M edical Academy, Nitte University, M angalore - 575018, Karnataka, India. \\ M obile : +91 8431644077 E-mail : arjchess_Ip@ rediffmail.com
}

\begin{abstract}
:
Dislocation of the elbow joint in association with fracture of radial head and fracture of coronoid process, is referred to as "terrible triad" of the elbow, the treatment of which provides a challenge to treating surgeon due to its complicated outcomes. The understanding of the elbow kinematics, the usage of various implants and surgical techniques in the recent years has led to the development of standard treatment protocols. The 'terrible triad' of the elbow is a severe injury that is difficult to treat and has a poor prognosis in the medium-toIong term. It is characterised most often by instability of the elbow, development of arthrosis and joint stiffness.

A 43 year old lady presented to us after a fall on outstretched dominant hand with severe pain and swelling around elbow. She had sustained a fracture of the radial neck and coronoid process with posterolateral dislocation of elbow. Immediate Closed reduction of the dislocation was performed under GA and elbow was immobilised in a plaster of paris slab for 3 weeks. She underwent operative procedure of open reduction and internal fixation of the radial head with a titanium plate and the coronoid process with a $4 \mathrm{~mm}$ screw and washer after 10 days.After 3 weeks elbow rehabilitation was begun and at one year post surgery there was signs of fracture healing with full range of motion of the elbow.
\end{abstract}

Keywords: Terribletriad of elbow, humeroulnar dislocation, radial head fracture, coronoid fracture.

\section{Introduction:}

Posterolateral dislocation of the elbow joint is the most common acute traumatic elbow instability and occurs secondary to a traumatic elbow injury due to axial loading in supinated forearm with valgus stress. ${ }^{5,6}$. Such trauma will induce damage to the radial collateral ligament complex extending to the capsule and up to the ulnar collateral ligament compartment ${ }^{6}$. Early treatment will affect the overall outcome. ${ }^{5}$ Dislocation of the elbow joint is often associated with ligament injury, fracture of radial head, coronoid process, oleocranon process or humeral epicondyles. The "terrible triad injury" of the elbow, as described by Hotchkiss, consists of a combination of 3

\begin{tabular}{|c|}
\hline Access this article online \\
\hline Quick Response Code \\
\hline
\end{tabular}

management of such injuries is to restore anatomical relations of bony structures of the elbow and stability of ligament complex so as to convert an unstable dislocated joint into ananatomically reduced and stable one. Early intervention result in a favourable outcome. ${ }^{7}$ The principles of this treatment were detailed by McKee et al. ${ }^{8}$ as well as Ring et al. ${ }^{9}$, however relatively few clinical reports are available in the literature.

\section{Case Report :}

A 43 year old lady presented to us after a fall on outstretched dominant hand with severe pain and swelling around elbow. On clinical evaluation, there was raised local temperature over the elbow, there was tenderness and crepitus with loss of three point bony relation of elbow without any neurovascular injury. Radiologically, fracture of the radial neck, fracture of the coronoid process with posterior humero-ulnar dislocation were noted. (Figure 1). Immediate Closed reduction of the dislocation was performed under GA and elbow was immobilised in a plaster of Paris slab. (Figures 2). Post operative CT scan 
(Figure 3) showed fracture coronoid process and radial neck and head in a displaced position. There was no incarceration of loose fragments in the joint. She was operatively treated after ten days when the swelling had subsided and an open reduction and internal fixation of the

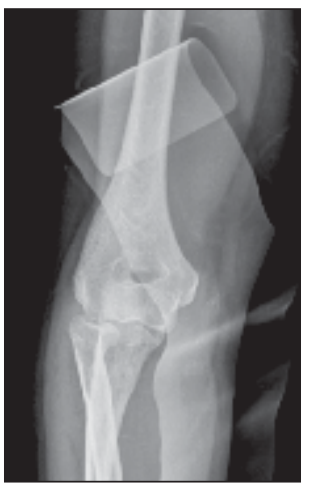

Fig $1 \mathrm{~A}$

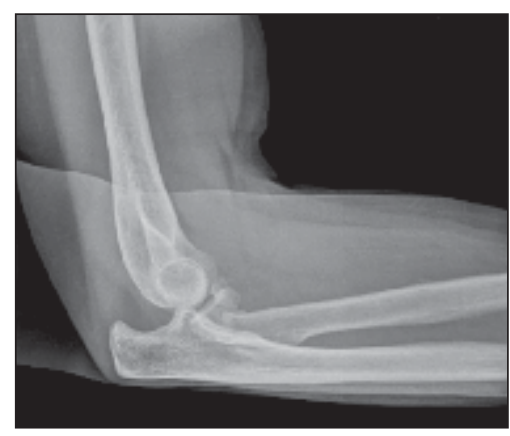

Fig 1 B
Fig 1(A/B): $A P /$ Lateral views of the elbow showing posterior dislocation of the elbow with fracture of the radial neck and coronoid process

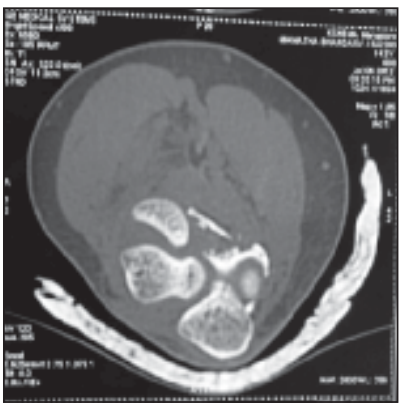

Fig $3 \mathrm{~A}$

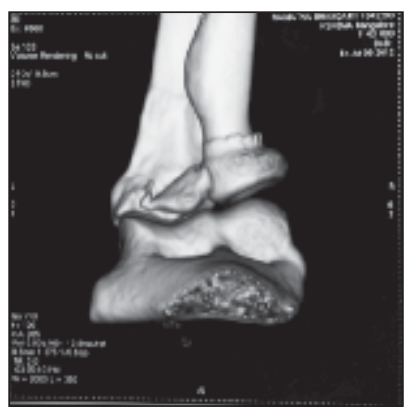

Fig 3 B
Fig 3 : (A) CT scan of the elbow after reduction, showing displaced radial neck and head and coronoid process fractures, (B) 3-dimensional reconstruction CT.

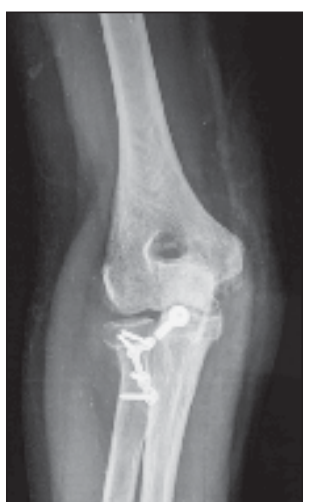

Fig $5 \mathrm{~A}$

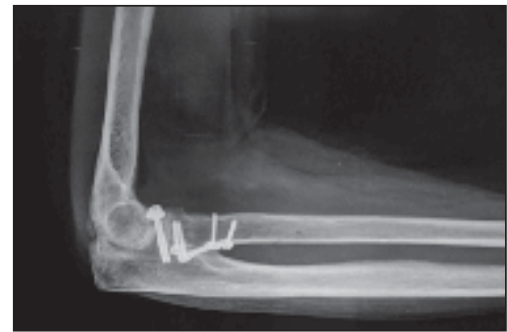

Fig 5 B
Fig 5(A/B): AP/Lateral views three months Post surgery showingsigns of healing of fracture with implant insitu radial head and neck with a titanium plate with $2.5 \mathrm{~mm}$ screws through the Kocher's approach and the coronoid process was fixed with a $4 \mathrm{~mm}$ titanium cannulated cancellous screw with washer through an antero-medial approach under general anaesthesia and following fixation

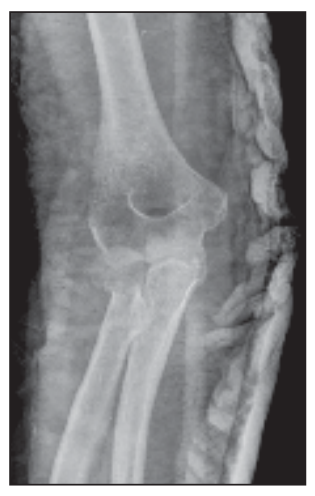

Fig $2 \mathrm{~A}$

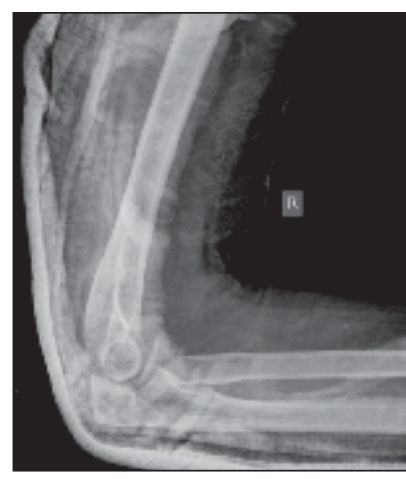

Fig 2 B
Figure 2(A/B): $A P /$ Lateral views after closed reduction and POP slab application of the elbow dislocation with displaced fracture fragments.

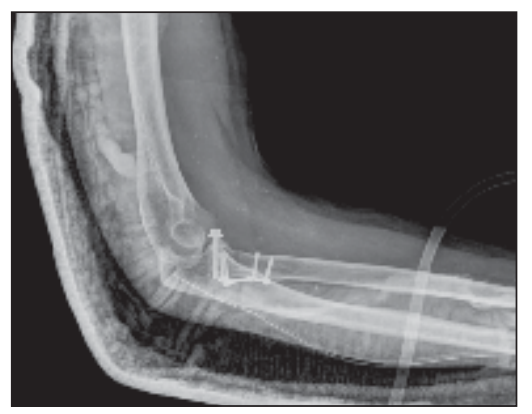

Fig 4: Post surgery $X$-ray of the elbow after open reduction and fixation with Titanium screws and plate with above elbow slab (Lateral view)

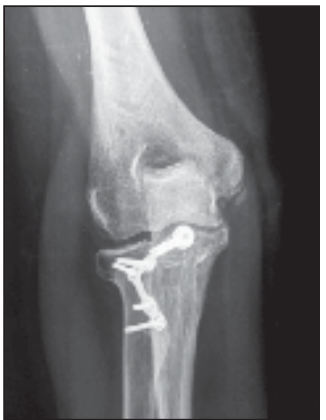

Fig $6 \mathrm{~A}$

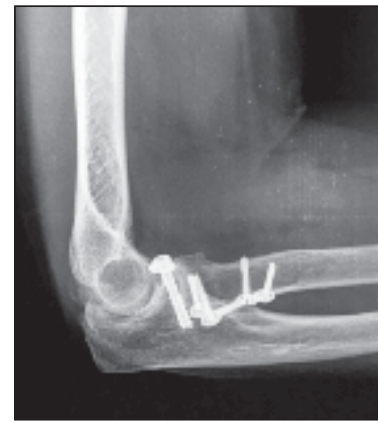

Fig 6 B
Fig 6(A/B): AP/ Lateral views at one year radiological union is noted at the fracture site 
stability of the elbow was assessed. The immobilisation was continued for a total period of three weeks to allow soft tissue healing. The post-surgery X-ray showed anatomical reduction (Figure 4). At the end of 3 weeks plaster slab and sutures were removed elbow rehabilitation was instituted with gentle active and active assisted flexion and extension and prono-supination

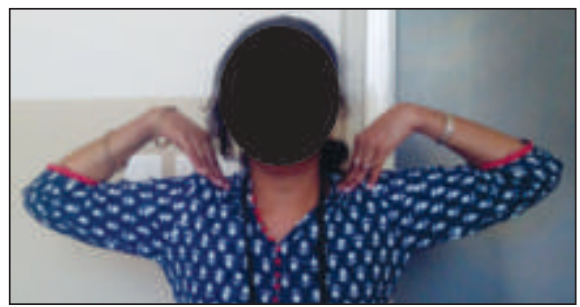

Fig 7(A) : Full range of elbow flexion

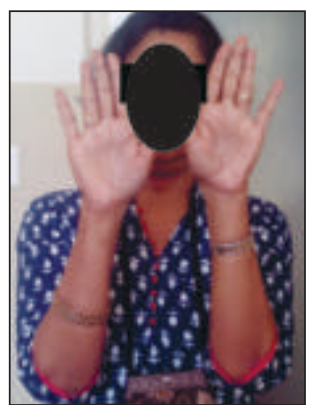

Fig 7(C) : Full range of elbow pronation

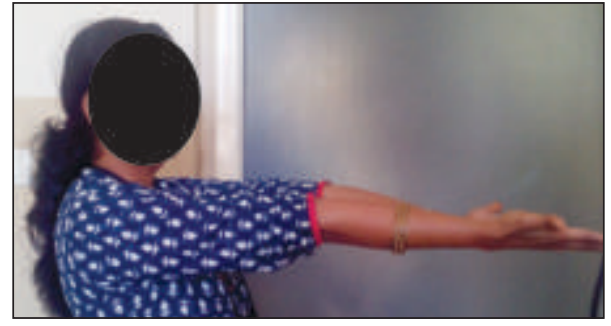

Fig 7(D) : Full range extension in full supination of elbow

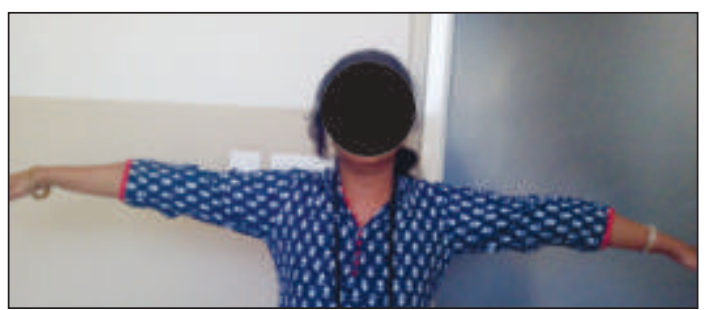

Fig 7(B):Full range of elbow extension

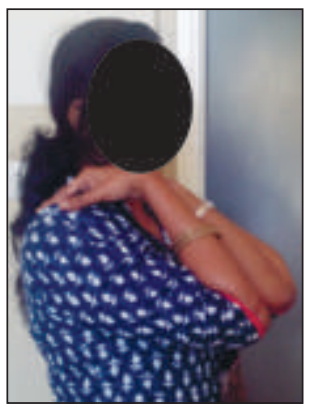

Fig 7(E): Full range of elbow flexion in full supination of elbow

\section{Discussion :}

The terrible triad of the elbow presents a challenge to surgeons and usually has poor outcomes, with frequent redislocation, arthrosis, loss of movement or. ${ }^{2,5,9,10}$. The most common injury mechanism is a simple fall on the outstretched hand, with axial transfer of the force on the hyper-extended elbow in supination and a position of elbow valgus. Despite the severity of the injury, the causative mechanism is not a high-energy trauma. ${ }^{8,9}$ The forces producing elbow luxation affect the joint by injuring structures sequentially from a lateral to medial direction. ${ }^{5}$ In the first phase, the lateral collateral complex is affected, which produces rotational instability of the elbow in varus. In the second phase, if the force continues to act, the radial head collides with the humeral condyle and fractures. In the third phase, the rotating instability produced by injury of the lateral complex enables the axial force to dislocate the elbow, usually in a posterior or postero-lateral direction, and occurs together with fracture of the coronoid process. ${ }^{11 .}$ The coronoid can also be affected at the beginning by rupture of the lateral ligament complex or by a direct impact of the humeral trochlea, although the second and third phases occur almost simultaneously. The medial ligament complex is also affected in most patients, but its injury is not an essential prerequisite for the terrible triad to occur. ${ }^{11 .}$ B. Chemama et al conducted a study, concluded that: The principle of the surgical management is based on two main objectives: restoration of bony stabilizing structures (radial head and coronoid process) and lateral collateral ligament reconstruction. A medial surgical approach is recommended in the case of persistent postero-lateral instability following lateral collateral ligament reconstruction or when fixation of a large coronoid process 
fragment is indicated. The use of an external fixator is only advocated in case of persistent instability following the reconstruction of bony and ligamentous structures. ${ }^{12}$. Roberto Seijas et al conducted a study on 18 cases of the terrible triad of the elbow on whom he performed various surgical treatment approaches and concluded that patients had better recovery of range of motion than those reported in other studies, the terrible triad of the elbow can lead to joint instability, arthrosis, and joint stiffness, and may resort to total elbow arthroplasty in some cases.

\section{References:}

1. Juan Rodriguez-Martin,Juan Pretell-Mazzini, Eva Maria AndresEsteban, and RicardoLarrainzar-Garijo. Outcomes after terrible triads of the elbow treated with the current surgical protocols. A review.IntOrthop. 2011 June; 35(6): 851-860.

2. Hotchkiss RN. Fractures and dislocations of the elbow. In: Rockwood CA, Jr, Green DP, Bucholz RW, Heckman JD, editors. Rockwood and Green's fractures in adults.Vol I, 4th ed. Philadelphia: LippincottRaven; 1996:929-1024.

3. Lill H, Korner J, Rose T, Hepp P, Verheyden, P, Josten C. Fracturedislocations of the elbow joint-strategy for treatment and results. Arch Orthop Trauma Surg 2001;121:31-7.

4. Pugh DM , M cKee MD. The "terrible triad" of the elbow. Tech Hand Up ExtremSurg 2002;6:21-9.

5. S.W. O'Driscoll, J.B. Jupiter, G.J.W. King, R.N. Hotchkiss, B.F. M orrey The unstable elbow J Bone Joint Surg Am, 82 (2000), pp. 724-738

6. S.W. O'Driscoll, B.F. Morrey, S. Korinek, A.D. Kai-Nan. Elbow subluxation and dislocation. A spectrum of instability.ClinOrthop, 280 (1992), pp. 186-197

7. A.D. Amstrong. The terrible triad injury of the elbow.CurrOpinOrthop, 16 (2005), pp. 267-270

8. M.D. M cKee, D.M.W. Pugh, L.M. Wild, E.H. Schemitsch, G.J.W. King. Standard surgical protocol to treat elbow dislocations with radial head and coronoid fractures. Surgical technique.J Bone Joint Surg Am, 87 (suppl. 1, part 1) (2005), pp. 22-32

9. D. Ring, J.B. Jupiter, J. Zilberfarb. Posterior dislocation of the elbow with fractures of the radial head and coronoid.J Bone Joint Surg Am, 84 (2002), pp. 547-551

10. Bousselmame N, Boussouga M, Bouabid S, Galuia F, Taobane H, Moulay I. Fractures of the coronoid process. Chir Main 2000;19:286-93.

11. Roberto Seijas, Oscar Ares-Rodriguez, Adolfo Orellana, Daniel Albareda, Diego Collado, ManelLlusa. Terrible triad of the elbow.J ournal of Orthopaedic Surgery 2009;17(3):335-9

12. B. Chemama, N. Bonnevialle, O. Peter, P. M ansatCorresponding author contact information, E-mail the corresponding author, P. Bonnevialle. Terrible triad injury of the elbow: How to improve outcomes? Orthopaedics \& Traumatology: Surgery \& Research Volume 96, Issue 2, April 2010, Pages 147-154
Our patient presented with a similar mode of injury and underwent the aforementioned management. She recovered with full range of motion and no instability or stiffness.

\section{Conclusion:}

Hence, we conclude that planned staged surgical intervention, anatomical restoration of the bony and ligamentous structures of the elbow with aggressive rehabilitation will possibly yield best possible outcome. 